


\title{
Centralised Labour Market Negotiations
}

\author{
Julia Müller \\ Thorsten Upmann
}

CESIFO WORKING PAPER NO. 4470

CATEGORY 4: LABOUR MARKETS

NOVEMBER 2013

An electronic version of the paper may be downloaded

- from the SSRN website:

- from the RePEc website:

- from the CESifo website:

WWW.SSRN.com

www.RePEc.org

www.CESifo-group.org/wp

\section{CESifo}




\title{
Centralised Labour Market Negotiations
}

\begin{abstract}
This paper contributes to the analysis of central vs. decentral (firm-level) labour market negotiations. We argue that during negotiations on a central scale employers and employees plausibly take output market effects into account, while they behave competitively during firm-level negotiations. Assuming that in both cases the labour market conflict is settled efficiently according to the familiar Nash bargaining solution, we show that central negotiations lead to a lower employment level but to a higher wage rate, when compared with local labour market bargains. While this is an important theoretical result in its own, it has important effects for both empirical labour market research and labour market policies. Also, this result counters the critique that efficient negotiations result in employment levels exceeding the competitive level.
\end{abstract}

JEL-Code: J510, J520, D410.

Keywords: central labour market negotiations, efficient bargains, Nash bargaining solution, involuntary unemployment, endogenous output price, Walrasian market clearing.

Julia Müller

Erasmus University Rotterdam

Erasmus School of Economics

Department of Applied Economics \&

Tinbergen Institute

PO Box 1738

The Netherlands - 3000 DR Rotterdam

jmuller@ese.eur.nl
Thorsten Upmann

University Duisburg-Essen

Mercator School of Management

Lotharstraße 65

Germany - 47057 Duisburg

Thorsten.Upmann@uni-duisburg-essen.de

November 3, 2013 


\section{Introduction}

There is a comprehensive literature on labour market negotiations between employers and employees. The interests of both groups are typically represented by either a firm and its workforce (or personnel) or by an employers' federation and a labour union, respectively. While the first pair captures the idea that negotiations take place on a local (or firm) level, the latter captures a situation where negotiations take place on a central (or industry) level. The distinction between local and central labour market negotiations may be inessential as long as broader aspects, such as output market competition or macroeconomic employment effects, are neglected. Yet, once some of these aspects becomes vital, the distinction between local and central labour market negotiations is essential. As we shall see, this holds true contrary to claims made elsewhere - even if firms behave competitively on the output market.

The fundamental distinction between local and central labour market negotiations originates from the parties' diverging perspectives and discrepancies in the coverage of the contracts. In local negotiations both parties take a firm-specific perspective and correspondingly ignore potential output market effects. In particular, if a firm behaves competitively on the output market, and thus regards output prices as exogenously given, there is no reason for the employer - and a fortiori for the employees - to take a different perspective in collective bargaining. In central labour market negotiations, though, both parties take an industry-wide perspective and, for that reason acknowledge the functioning of the output market, irrespective of the actual behaviour of individual firms. In this sense the employers' association and the labour union have a broader, more comprehensive perspective on markets than has each single firm. As a consequence, even if firms behave competitively, the bargaining parties would not regard output prices as exogenously given, but plausibly and reasonably anticipate output market effects. Hence, while the assumption of competitive behaviour with regard to the output price is a reasonable assumption for bargaining parties on a local scale, this becomes a questionable assumption for central labour market negotiations.

This argument also provides an alternative perspective on the difference between local and central labour market negotiations. While local negotiations can be identified with bargaining parties regarding output prices as exogenously given, central labour market negotiations can be identified with parties taking into account the endogeneity of output prices. Then, local and central negotiations coincide only if the output price is actually fixed (which may happen, for example, when the good 
is traded on international markets). ${ }^{1}$ From this perspective, local labour market negotiations may be interpreted as negotiations under a fixed output price regime; and central negotiations, as negotiations under an endogenous (variable) price regime. From this perspective, local and central negotiations may be identified with negotiations under fixed and endogenous output prices, respectively.

In this paper we elaborate on the difference between local and central labour market negotiations - or according to the last comment, on the difference between negotiations under a fixed and an endogenous output price regime. In order to scrutinize this difference most pronouncedly, we assume that firms behave competitively on the output market, and then derive the equilibrium outcome of the labour market for both central and local labour market negotiations. As an equilibrium concept for the labour market, we employ the familiar Nash bargaining solution. Presuming that the parties negotiate on both the wage rate and the employment level, this bargaining agenda allows them to reach a Pareto efficient outcome. ${ }^{2}$ Contrasting the outcome under local and central labour market negotiations, we find that there is a significant, uniquely signed difference between both models. While under local labour market negotiations the equilibrium employment level is determined according to the well-known "Nash curve", the equilibrium outcome under central bargains is determined by a suitably modified version of the Nash curve, which lies to the left of the latter. Correspondingly, under central labour market negotiations the resulting equilibrium contract consists of a lower employment level but a higher wage rate when compared with the outcome under local bargaining. This employment effect may be sufficiently large such that equilibrium employment under central bargaining (viz. endogenous output price) may fall short of the competitive employment level.

These findings are notable in various aspects. Firstly, by enhancing the understanding of the effects of centralisation our analysis contributes to the theory of labour economics. Secondly, efficient bargains are sometimes criticised as equilibrium employment exceeds the competitive level. Irrespective of whether one regards this critique as justified or not, our analysis helps to counter this criticism as it

\footnotetext{
${ }^{1}$ This observation explains that "a model with the property that the outcome of the wage bargaining is independent of the degree of centralization", as considered by Hoel (1990, p. 454), can be justified when the output price is fixed.

${ }^{2}$ The findings of the empirical literature on whether labour market equilibria lie on the labour demand curve or on the Pareto curve are mixed - a result that comes hardly at surprise given the immense variety of institutional differences in labour markets. A substantial list of references which find empirical evidence in favour of efficient bargains is provided by Upmann and Müller (2013); and a valuable literature survey, by Lawson (2011).

Moving a step back further, the labour market institutions themselves may be endogenised; attempts in this direction have been undertaken by, for example, Dobson (1997); Vlassis (2003); Petrakis and Vlassis (2000, 2004); Kraft (2006).
} 
shows that even under efficient bargains equilibrium employment may fall short of its competitive level once output price effects are acknowledged; in this sense, this paper bolsters an efficient bargains approach. Thirdly, for both labour market scenarios (central and local negotiations) we provide two easily comprehensible and directly accessible equilibrium conditions (viz. the Pareto curve and the respective Nash curve) which may directly be tested empirically.

The papers presumably closest to ours are Davidson (1988) and Dowrick (1989). Davidson (1988) compares local (firm-specific) and centralised wage negotiations (right-to-manage approach) for a unionised duopoly with constant marginal cost. The bargaining process is modelled as a non-cooperative game, viz. as Rubinstein's alternating-offer game. Davidson finds that central negotiations result in higher wages than do local negotiations, arguing that this effect comes about because an industry union internalises a positive "externality": the effect that a higher wage negotiated in one firm increases the pie to be negotiated in another firm. While Davidson arrives at this result for a duopoly, we show that basically the same result carries over to competitive markets. In this way we show that Davidson's conjecture (p. 399) that "this externality is not present in competitive markets since an increase in the wage paid by any given firms has a negligible effect on all other firms" is flawed: In central negotiations the parties take into account the endogeneity of the output price, and in this sense they "internalise an externality". 3 The crucial point is that labour market contracts induce (equilibrium) output and thus price effects, and that although firms behave competitively, the labour market parties on a central scale do not behave so, but anticipate these effects.

Similarly, Dowrick (1989) also considers centralised versus decentralised labour market negotiations in an oligopolistic industry with linear costs, but applies a cooperative bargaining model. Comparing negotiations on wages (right-to-manage model) with negotiations on wages and employment (efficient bargains), he observes that "the effects of union wage coordination [i.e. centralisation] depend on the bargaining structure", and finds in the case of efficient bargains (p. 1138): "When bargaining is efficient [...], implying no direct link between wages and employment, there is no incentive for competitive wage-cutting so union coordination on wages should not affect the industry outcome." Our analysis demonstrates that the latter conclusion is (generally) incorrect. Assuming an endogenous output price, it is the employers' federation that faces an incentive to reduce employment, and in this way to restrict output, so as to induce a higher output price. It thus appears to us that (part of) the literature has focused too much on the incentives of the trade union

\footnotetext{
${ }^{3}$ Clearly, this type of an "externality" is not a proper externality in the sense of Viner (1931), whose definition is regarded as the standard definition nowadays.
} 
(the preferences of which are in fact not affected in this framework), and has ignored the discrepancy in the preferences between a single firm (decentralised negotiations) and the employers' federation (centralised negotiations).

The rest of this paper is structured as follows. We begin with central labour market negotiations. In Section 2 we specify the preferences of labourers and firms, from which we deduce the preferences of the negotiating parties in Section 3. Then, in Section 4 we characterise the equilibrium of the labour market under central negotiations. In order to be able to explore those effects attributable to the fact that negotiations take place on a central level (viz. attributable to the endogeneity of the output price), we present the equilibrium under local bargains (viz. in case of an exogenously fixed output price) in Section 5; with this at hand, we then contrast both equilibria in Section 6. Finally, we conclude in Section 7.

\section{The Model}

Consider an industry consisting of some arbitrary but fixed number (or mass) of firms $n$. These firms produce a homogeneous output good by means of labour and capital, which represent the only variable factors of production and are combined with some unspecified fixed factor(s). Firms behave competitively on both factor markets and on the output market.

Before production can take place and output can be sold on the market, labour must be hired and therefore wages be negotiated. The determination of wages and employment is accomplished by central labour market negotiations between an employers' federation and a labour union which negotiate a contract on both variables. (The modifications required for local labour market negotiations are explained in Section 5.) This contract, once negotiated and signed, is authoritative for all firms. With labour market agreements being conclusive and binding for firms, capital is left as the only variable at their discretion. We thus have a sequence of decisions: At the first stage bargaining between an industry labour union and an employers' federation takes place; then firms, following suit the labour market contract, employ labourers, pay wages and decide on the amount of capital to be deployed; then, production takes place, and eventually output is sold on the output market. ${ }^{4}$

While the employers' federation represents the interest of all firms, the labour union acts on behalf of all workers. Hence, both bargaining parties are industry-wide

\footnotetext{
${ }^{4}$ Hoel (1990) and Fagnart and Germain (1997) consider models with (long-run) investments where the amount of capital has to be determined previous to wage-negotiations (right-to-manage model); and Cripps (1997) analyses the equilibrium timing of investment decision and wage bargaining under uncertainty.
} 
organisations covering all firms respectively all workers of the industry. Assuming a sufficient amount of rationality, both the labour union and the employers' federation understand the functioning of the output market and take into account the consequences of their bargaining agreement on the equilibrium of the output market. That is, the bargaining parties correctly anticipate the equilibrium on the output market which is subsequently induced by their agreement - and in this sense labour market negotiations take place at a central level. ${ }^{5}$

We now specify the behaviour of firms and the objective function of the employers' federation, along with the preferences of individual workers (union members) and the objectives of the labour union in a consistent way. Also, we have to be specific about how the labour market conflict is solved. We begin with households' preferences, specify the union's objective function, and then turn to the firms and the employers' federation. Finally, we describe the output market and the equilibrium thereof.

Labourer Households. On the supply side of the labour market, there is a mass of $N$ labourer households, ${ }^{6}$ all of which we assume to have identical preferences and productivity. Each household derives utility from (private) consumption and leisure time, with $v: \mathbb{R}_{+} \times[0, T] \rightarrow \mathbb{R}_{+}$representing the corresponding utility function, where $T(T>1)$ denotes individually disposable time. Consumption is treated as an aggregate commodity, the price of which we normalize to unity. Disposable time can either be consumed as leisure time or used for working. For, say, institutional reasons each household either can accept a full employment contract and work the usual weekly working time, or does not work at all and consumes its total disposable leisure time. Normalizing the regular working time to unity, an employed household receives a real wage income equal to the net (real) wage $w$. An unemployed household obtains some fixed non-labour income $b$, which may be interpreted, for example, as unemployment benefits, subsistence income or non-labour income. Correspondingly, an employed worker attains a utility level of $u(w):=v(w, T-1)$; and an unemployed worker, of $\bar{u}:=v(b, T)$. We assume that $u^{\prime}(w)>0, u^{\prime \prime}(w)<0$ for all $w \geq 0$, and that there exists $\bar{w} \geq 0$ with $u(\bar{w})=\bar{u}$. Hence, $\bar{w}:=u^{-1}(\bar{u})$ is the reservation wage below which no household is willing to work; that is, aggregate labour supply equals zero for all $w<\bar{w}$, equals $N$ for all $w>\bar{w}$, and is indeterminate, i.e., equals $[0, N]$ for $w=\bar{w}$. As a consequence, when $L^{a g g}$ denotes aggregate employment, the class of all workers consists of $L^{a g g}$ employed and $N-L^{a g g}$ unemployed households.

\footnotetext{
${ }^{5}$ We follow the familiar approach, established by Oswald (1982) and others, that in central negotiations (industry-wide) parties take into account the market clearing conditions of the output market.

${ }^{6}$ For ease of presentation we shall subsequently speak of $N$ as the number of labourer households.
} 
Firms. The production sector is characterized by $n(n \geq 1)$ identical firms producing a homogeneous output good. Each firm $i, i \in I:=\{1, \ldots, n\}$, produces its output by means of three factors: labour $\left(L_{i}\right)$, variable capital $\left(K_{i}\right)$, and some fixed factor, which can be interpreted as land or fixed capital etc. While the factor price of labour, given by the wage rate $w$, is endogenously determined, the (rental) price of variable capital, denoted by $r$, is exogenously given. The production technology features constant returns to scale with respect to all factors. For convenience, we omit the fixed factor(s) as an argument of the production function, and thus write output of firm $i$ as $Q_{i}=f\left(L_{i}, K_{i}\right)$, so that $f$ features decreasing returns-to-scale (with respect to the variable factors). We naturally assume that $f$ is monotonically increasing, twice continuously differentiable, and strictly concave in both arguments; moreover, we assume $f_{K K} f_{L}-f_{K L} f_{K}<0$. (Subindices of $f$ denote partial derivatives.) Denoting the output price by $p$, the profit of firm $i$ amounts to

$$
\pi\left(w, L_{i}, K_{i}\right)=p f\left(L_{i}, K_{i}\right)-w L_{i}-r K_{i}
$$

Since the employment level (as well as the wage rate) is negotiated between the labour union and the employers' association, each firm is left with the decision on the level of capital only. Assuming price-taking behaviour, each firm $i, i \in I$, maximizes its profit with respect to $K_{i}$, for any given employment level $L_{i}$ and any given price vector $(p, w, r)$. Correspondingly, firm $i$ equates the value of the marginal product of capital to its factor price; that is, capital demand, $K_{i}=\kappa_{i}\left(L_{i}, p, r\right)$, and market supply, $Q_{i}=\xi_{i}\left(L_{i}, p, r\right)$, are implicitly defined by

$$
\begin{aligned}
p f_{K}\left(L_{i}, K_{i}\right) & =r \\
f\left(L_{i}, K_{i}\right) & =Q_{i} .
\end{aligned}
$$

Carefully note that capital demand, and thus output supply, does not depend on the wage rate. Since the rental price of capital is fixed by assumption, we suppress $r$ as an argument of both $\kappa_{i}$ and $\xi_{i}$ and simply write $K_{i}=\kappa_{i}\left(L_{i}, p\right)$ and $Q_{i}=\xi_{i}\left(L_{i}, p\right)$ subsequently.

Since firms are symmetric by assumption, the functions $\kappa_{i}$ and $\xi_{i}$ must be the same for all firms so that capital demand and output are given by $K_{i}=\kappa\left(L_{i}, p\right)$ and $Q_{i}=\xi\left(L_{i}, p\right)$ respectively for all $i \in I$. Accordingly, whenever the negotiated level of aggregate employment is distributed equally among firms — which we shall naturally assume henceforth — capital demand and output are equalised among firms: $K_{i}=K=\kappa(L, p)$ and $Q_{i}=Q=\xi(L, p)$ for all $i \in I$.

Output Market. Using this symmetry, aggregate supply equals $Z=\sum_{j=1}^{n} Q_{j}=$ $n Q$, and in any equilibrium of the output market, the output price must accomplish 
to equalise demand and supply. Demand for this good is represented by an inverse demand function $p: \mathbb{R}_{+} \rightarrow \mathbb{R}_{+}$, which we assume to be strictly decreasing and continuously differentiable for all relevant quantities of output, $Z{ }^{7}$ Then, using symmetry of firms, the competitive equilibrium of the output market is characterised by

$$
\begin{aligned}
p(Z) f_{K}(L, K) & =r, \\
f(L, K) & =Q, \\
n Q & =Z,
\end{aligned}
$$

where condition (5) represents the supply identity. Equations (3)-(5) determine, for any given value $L$, the values of capital, per-firm output and aggregate output in a symmetric equilibrium of the output market. In order to distinguish between the (identical) firm-level demand and supply functions on the one hand and the symmetric market equilibrium on the other hand, we write $K=k(L), Q=q(L), Z=$ $z(L)$ for the latter. (The derivatives of these functions are derived in Appendix A. $)^{8}$

\section{Labour Market}

The equilibrium on the labour market is given by the outcome of central bargains between a labour union and an employers' federation. We first characterise the objective function of both parties and then define the equilibrium concept which determines the equilibrium outcome of the labour market.

The Labour Union. On the supply side of the labour market, there is a labour union which represents the mass of all $N$ labourer households. The labour union seeks to maximize the sum of its members' utilities, which is given by $L^{a g g} u(w)+\left(N-L^{a g g}\right) \bar{u}$, when $L^{a g g}$ denotes industry-wide aggregate employment. ${ }^{9}$ The union's reservation utility is given by $N \bar{u}$, viz., when all its members are unemployed. For any fixed membership $N$, the union's preferences can thus be represented by $L^{a g g}[u(w)-\bar{u}]+N \bar{u}$. Since $u(w)$ denotes the utility obtained by a (fully) employed worker, and $\bar{u}$ represents the utility of an unemployed household, the union's preferences can alternatively be written as $N\left[\frac{L^{a g g}}{N} u(w)+\frac{N-L^{a g g}}{N} \bar{u}\right]$ and interpreted

\footnotetext{
${ }^{7}$ By relevant quantities we mean all $Z \in\left(0, Z^{+}\right)$, where $Z^{+}:=\min \{Z \mid p(Z)=0\}$, with the usual convention $\min \{\}=+\infty$.

${ }^{8}$ Carefully note the difference between the (identical) firm-level demand and supply functions $\kappa$ and $\xi$ and the symmetric market equilibrium determined by $k, q$ and $z$.

${ }^{9}$ This standard specification of a trade union can be traced back to Oswald (1982), at latest.
} 
as the representative labourer's expected utility, provided that the probability of employment is the same for all labourers, that is, equal to $L^{a g g} / N$.

Following a standard assumption in the literature (cf., for example, Dowrick, $1989,1993)$, we assume that the utility of the industry trade union is the sum of the utilities of its constituents. Using the fact that aggregate employment is split equally among firms, so that $L^{a g g}=n L$, we express, for convenience, the preferences of the union in terms of per-firm employment rather than in terms of aggregate employment:

$$
\Psi(w, L):=n L[u(w)-\bar{u}]+N \bar{u} .
$$

Differentiation of the union's utility with respect to (per-firm) employment and the wage, holding utility constant, yields

$$
\left.\frac{d w}{d L}\right|_{\Psi \text { const. }}=-\frac{u(w)-\bar{u}}{L u^{\prime}(w)}<0 \quad \forall w>\bar{w}
$$

The union's indifference curves are thus downward sloping and lie above the reservation wage $\bar{w}:=u^{-1}(\bar{u})$ for all wages exceeding the reservation wage.

The Employers' Association. On the labour demand side there is an employers' association which acts in accordance with the interest of the firm owners and thus seeks to maximize firms' aggregate (derived) profits,

$$
\Pi(w, L):=n \pi(w, L, k(L))=n[p(z(L)) q(L)-w L-r k(L)],
$$

with $q(L)=f(L, k(L))$ and $z(L)=n q(L)$. Differentiating $\Pi$ with respect to $L$ and $w$, one obtains the slope of the employers' indifference curves (or of the industry iso-profit curves):

$$
\left.\frac{d w}{d L}\right|_{\Pi \text { const. }}=-\frac{w-p(z(L)) f_{L}(L, k(L))-\phi(L)}{L},
$$

where

$$
\phi(L):=p^{\prime}(z(L)) z^{\prime}(L) q(L),
$$

or $\phi=p^{\prime} q z^{\prime}$ for short. (Alternatively, $\phi$ may be written as $\phi=\varepsilon^{p} \varepsilon^{z} \frac{p q}{L}$, where $\varepsilon^{p}$ and $\varepsilon^{z}$ denote the elasticities of inverse demand and aggregate supply, respectively.) Accordingly, the iso-profit curves are increasing in $L$ until $p f_{L}(L, K)+\phi=w$, and decreasing afterwards. In other words, for any given wage rate, the employment level which maximizes aggregate profit is the locus of points where the slope of the aggregate iso-profit curve is equal to zero:

$$
p(z(L)) f_{L}(L, k(L))+\phi(L)=w .
$$


Condition (8) determines the representative firm's employment level when industrywide profits are maximized. Since the number of firms is fixed, condition (8) likewise yields the profit-maximising level of employment, when the endogeneity of the output price $p$ is taking into account.

Since the objective of the employers' association is maximisation of aggregate profits, it is in its innate interest to take into account the endogeneity of the output price. This makes the association to consider, for any given $w$, a level of $L$ defined by condition (8) to be optimal; we refer to this as centralised labour demand. Carefully note that this type of labour demand differs from (ordinary) labour demand of a single firm, which is implicitly given by

$$
p f_{L}(L, K)=w .
$$

Since the right hand sides of equation (8) and equation (9) differ by the term $\phi=$ $p^{\prime} q z^{\prime}<0$, the endogeneity of the output price accounts for the difference between labour demand of a single firm, defined by equation (9), and centralised labour demand, given by equation (8). More precisely, $\phi$ represents the equilibrium price effect induced by a marginal and symmetric increase in employment by all firms on the revenue of each firm. Intuitively, since firms behave competitively, each firm disregards any potential price effects on profits, including its own, while the employers' association, acting on behalf of the whole industry, arguably realises these price effects - and thus considers a modified version of the labour demand curve, given by equation (8).

It follows from the negativity of $\phi$ that, for any given point $(L, w)$, the isoprofit curve of a single firm is steeper than the iso-profit curve of aggregate profits (evaluated along the equilibrium path of the output market). Correspondingly, from the point of view of the employers' association, the induced negative price effect decreases the effective marginal product of labour. This reduction in the productivity of labour decreases labour demand - and correspondingly the aggregate labourdemand curve lies to the left of the labour demand curve of a single firm.

\section{Central Labour Market Bargains}

Having characterised the preferences of both parties, we now turn to the equilibrium bargaining outcome. We assume that the employers' association and the industry labour union understand the functioning of competitive markets, and acknowledge that the output price adjusts according to Walrasian market clearing. Being aware of the endogeneity of the output price, the labour union and the employers' association, both acting on behalf of their members' interest, take into account the consequences 
of their agreement on the subsequent market equilibrium. Also, presupposing a sufficient amount of rationality, the two parties will not forgive any potential gain from bargaining - and will thus not stop their negotiations short of a Pareto efficient outcome. ${ }^{10}$ For this reason, we assume that labour market negotiations cover both the wage rate and the employment level.

We follow the usual approach in the literature and assume that the bargaining outcome can be described by the asymmetric Nash bargaining solution. (Yet, other Pareto efficient solution concepts are equally suitable to demonstrate our main argument put forth here.) We denote the relative bargaining power of the labour union by $\mu \in[0,1]$, and that of the employers' federation by $1-\mu$. Let the disagreement utilities of the union and the employers' association be given by $N \bar{u}$ and 0 , respectively. As explained before, both parties anticipate that, after the bargaining conflict is settled, each firm selects capital according to the demand curve, $K=k(L)$.

The Nash bargaining solution (in the $(w, L)$-space) may be characterized as the solution of the following maximization problem:

$$
\max _{w, L}[\Psi(w, L)-N \bar{u}]^{\mu}[\Pi(w, L)]^{1-\mu} .
$$

For convenience we define the elasticity of excess utility from a given wage rate by $\sigma(w):=w u^{\prime}(w) /(u(w)-\bar{u})$. Then the first order conditions of this maximization problem for $w$ and $L$ read as (omitting arguments) ${ }^{11}$

$$
\begin{array}{rlrl}
w & & 0 & =\mu \pi u^{\prime}(w)-(1-\mu) L(u(w)-\bar{u}), \\
\Leftrightarrow \quad \sigma(w) & =\frac{1-\mu}{\mu} \frac{w L}{\pi}, \\
L: & 0 & =\mu \pi+(1-\mu) \underbrace{\left(\phi+p f_{L}-w\right)}_{=(1 / n) \partial \Pi(w, L) / \partial L} L, \\
\Leftrightarrow & w & =\mu \frac{p f(L, K)-r K}{L}+(1-\mu)\left(p f_{L}+\phi\right) .
\end{array}
$$

We subsequently refer to equations (10) and (11) as the $w$-Nash and the $L$-Nash

\footnotetext{
${ }^{10}$ Gerber and Upmann (2006) and Upmann and Müller (2013) present additional descriptive and normative arguments in favour of Pareto efficient bargains. Beyond this, Kraft (2006) provides a game-theoretic argument in favour of efficient bargains: He shows that when oligopolistic firms are free to choose between negotiations covering the wage rate and employment or covering the wage rate only, it is a dominant strategy to opt for wage-employment negotiations.

${ }^{11}$ In order to reduce notational effort, we refrain from specifically marking the equilibrium values of $w$ and $L$. Instead, subsequently all variables are understood as the equilibrium values of the labour market. Also, to ease the presentation of formal results, we frequently suppress arguments of function in the subsequent analysis, whenever we believe that no misunderstanding should arise.
} 
curve, respectively. Since condition (11) is equivalent with

$$
\frac{1-\mu}{\mu} \frac{w L}{\pi}=\frac{w}{w-p f_{L}-\phi}
$$

it immediately follows from equations (10) and (11) that the bargaining outcome must satisfy

$$
\sigma(w)=\frac{w}{w-p f_{L}-\phi} .
$$

Carefully note that equation (12) may alternatively be derived by equalizing the slopes of the indifference curve of the bargaining parties:

$$
\left.\frac{d w}{d L}\right|_{\Psi \text { const. }}=-\frac{u(w)-\bar{u}}{L u^{\prime}(w)}=-\frac{w-p f_{L}-\phi}{L}=\left.\frac{d w}{d L}\right|_{\Pi \text { const. }} .
$$

Since equalizing the slopes of the parties' indifference curves characterizes Paretoefficient allocations (in the $(L, w)$-space), condition (12) is also referred to as the Pareto-curve (or the contract-curve). ${ }^{12}$ The parties' indifference curves are depicted in Figure 1. Therein the thin dashed curves represent indifference curves of the employers' federation (iso-profit curves), while the thin continuous curves represent indifference curves of the labour union. The resulting Pareto-curve, i. e. the locus of points in the $(L, w)$-space where the indifference curves of the labour union and the employers' association are tangent to each other, is parameterized in $\mu$ and depicted by the solid red curve and denoted by $\mathcal{P}$. In particular, the zero-profit curve, indicated by $\Pi=0$, represents the indifference curve of the employers' association with the lowest individually rational utility level. Finally, the downward sloping solid purple curve, denoted by $\mathcal{L}^{e}$, depicts the the centralised labour demand curve $p f_{L}+\phi$.

Since the labour union is only interested in contracts that guarantee $u(w)>$ $\bar{u} \Leftrightarrow w>\bar{w}$, equation (12) implies $w>p f_{L}+\phi$, and therefore $\sigma(w)>1$. The Pareto curve thus lies above the reservation wage, and it only intersects the latter when $u(w)=\bar{u}$, i. e., when $w=\bar{w}$. Graphically, the Pareto curve originates at the point of intersection of the centralised labour demand curve with the reservation wage, i. e., at $(\bar{L}, \bar{w})$, and terminates at the zero-profit curve, i. e., at $(\hat{L}, \hat{w})$.

For efficient Nash bargains the labour-market equilibrium can thus determined by the condition of Pareto-efficiency, equation (12), together with the $L$-Nash curve, equation (11). ${ }^{13}$ Following the standard nomenclature in the literature, we sometimes refer to the latter equation, more precisely the graph defined by equation (11),

\footnotetext{
${ }^{12}$ Differentiation of equation (12) with respect to $L$ and $w$ reveals that the contract curve is upward sloping as long as $u$ is strictly concave, and is vertical if $u$ is affine.

${ }^{13}$ Clearly, the bargaining outcome is alternatively characterized by conditions (10) and (11), or by conditions (10) and (12). But we follow the literature which usually defines the efficient Nash bargaining solution by the Pareto- and the $(L-)$ Nash-curve.
} 


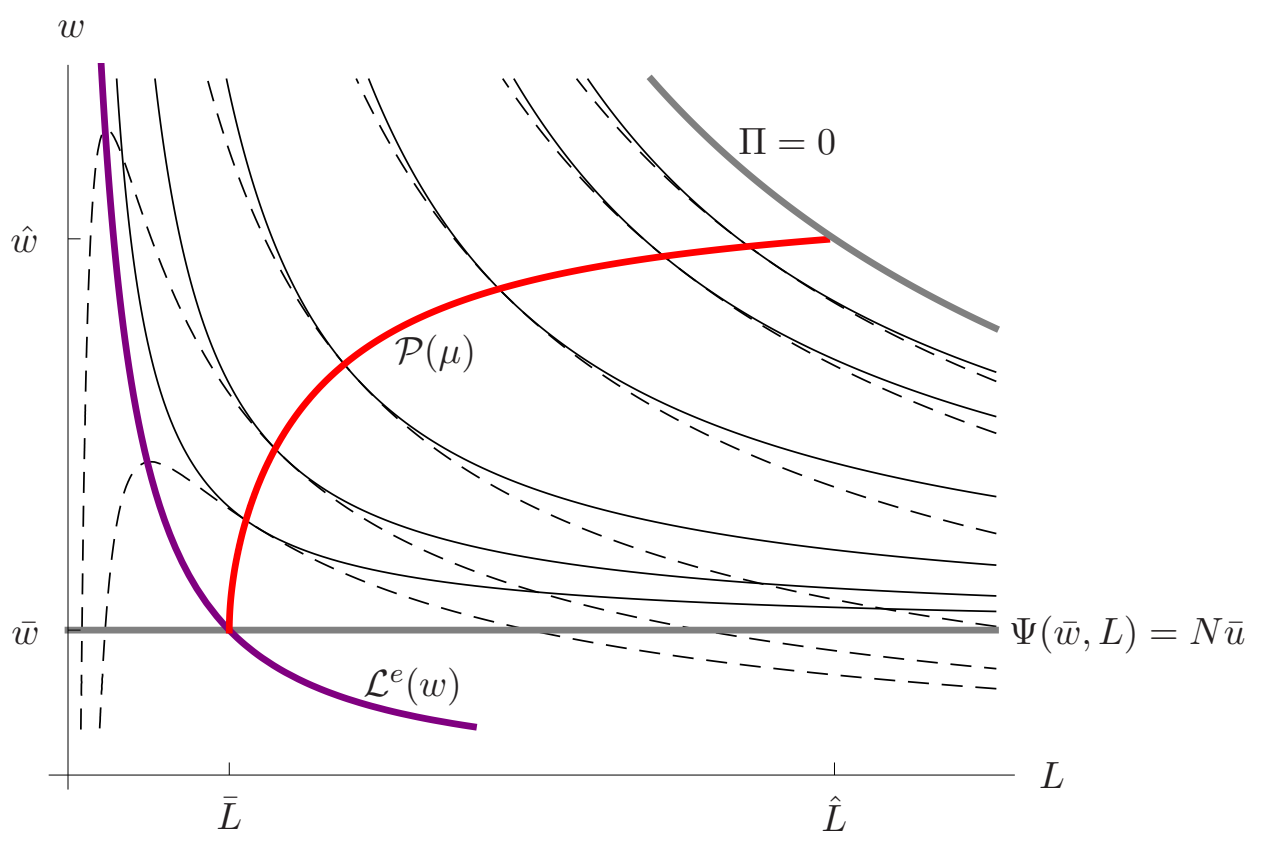

Figure 1: Parties' indifference curves and Pareto efficient allocations

as the Nash-curve (in the $(L, w)$-space). ${ }^{14}$ Descriptively, by intersecting with the Pareto-curve only once, the Nash curve determines a particular point on the former, and thus yields a unique Pareto-efficient outcome. ${ }^{15}$ This situation is illustrated in Figure 2. Therein the decreasing red curve is the Nash curve, or more precisely the $L$-Nash curve, denoted by $\mathcal{N}_{L}$, while the blue curve is the $w$-Nash curve, denoted by $\mathcal{N}_{w}$. By construction, both intersect with the Pareto curve at the same point: at the Nash bargaining outcome, denoted by $\left(L^{N}, w^{N}\right)$.

Note that the $L$-Nash-curve (11) defines the negotiated wage rate as the weighted average of the net average and the "aggregate" marginal product of labour, where the latter is to be understood as the marginal product of a simultaneous and equal small increase in employment by all firms on aggregate profit defined as $w^{*}(L):=p f_{L}+\phi$. Hence, the Nash-curve lies everywhere above the centralised labour-demand curve, but below the zero-profit-curve. Since $\phi<0$, it is as if the marginal product of labour were reduced by the endogeneity of the output price.

\footnotetext{
${ }^{14}$ Yet, the reader is alerted that this nomenclature is somewhat imprecise and potentially misleading. Since equation (10) and equation (11) depend on the solution concept, it is more precise to refer to both as Nash curves, namely as the $w$ - and the $L$-Nash curve respectively (just as introduced on page 10). Accordingly, only when no misunderstanding is expected to arise, do we refer to the $L$-Nash curve as the Nash curve.

${ }^{15} \mathrm{Had}$ we chosen another (efficient) solution concept, the Nash curve had been substituted by another curve (generically) selecting a different point on the (unchanged) Pareto curve.
} 


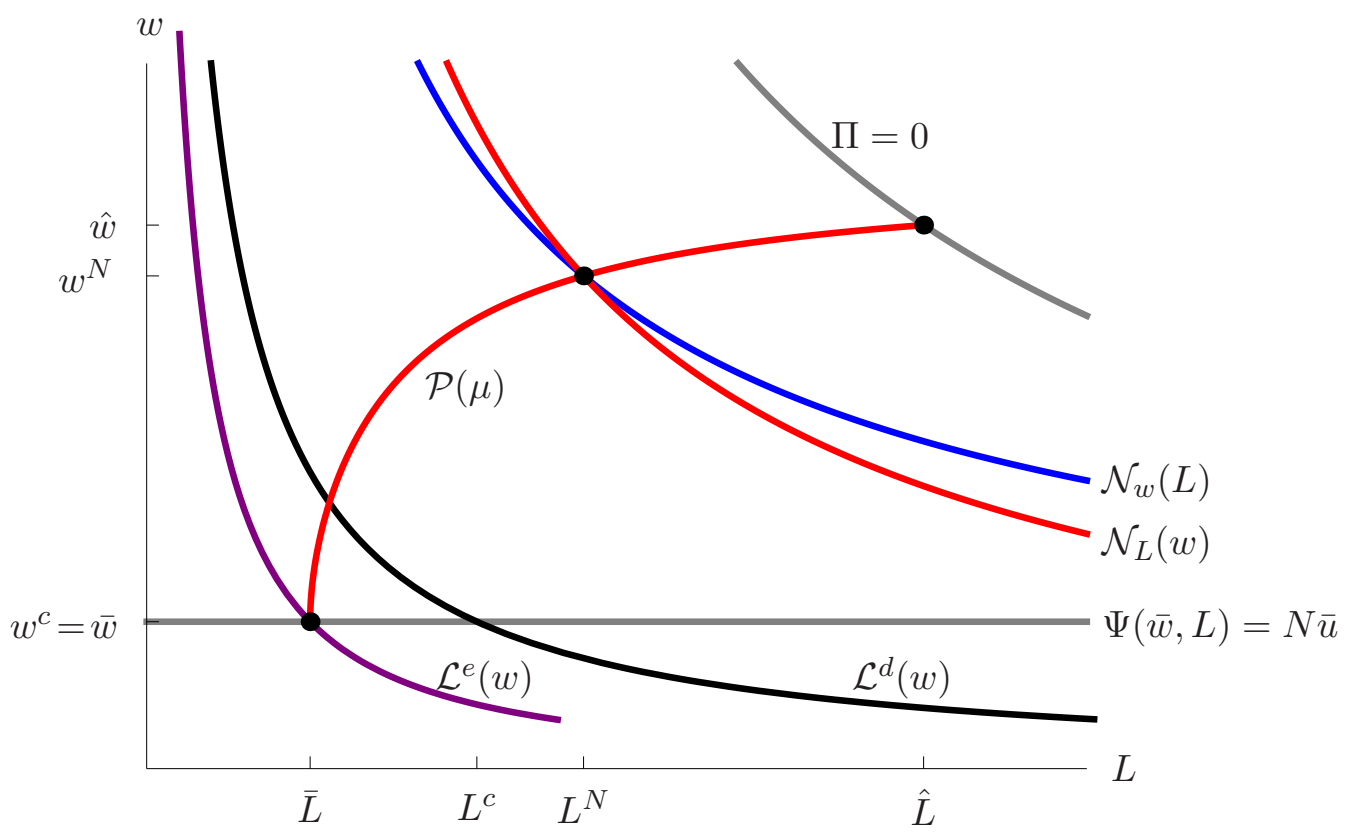

Figure 2: Nash solution for central labour market negotiations

In this sense, $w^{*}(L)$ represents the marginal product of labour corrected for the output-price effect, viz. the marginal revenue of labour when all firms increase employment by the same small amount (henceforth the aggregate marginal revenue of labour for short). With the definition of $w^{*}$ at hand, the negotiated wage rate may, alternatively, be written as

$$
w=w^{*}(L)+\mu \frac{p f(L, K)-r K-w^{*}(L) L}{L} .
$$

The negotiated wage thus equals the marginal revenue of labour plus a mark-up which is proportional to the potential profit per worker if the wage were equal to $w^{*}(L)$. Note that the higher the union's bargaining power, the higher is ceteris paribus the mark-up, implying that the wage rate increases with the bargaining power of the labour union. ${ }^{16}$ In the polar case where the union has no bargaining power $(\mu=0)$, the mark-up vanishes and the wage equals the reservation wage $w=w^{*}=\bar{w}$. Since $\bar{w}$ is the lowest acceptable wage for the trade union, the contract $(\bar{L}, \bar{w})$ (where $\bar{L}$ is defined as the solution of $w^{*}(L)=\bar{w}$ ) is the worst, individually rational contract for the union, and thus represents the lower end of

\footnotetext{
${ }^{16}$ To our knowledge, the first The fact that the mark-up depends on the relative bargaining strength of the firm and the union has been shown previously by Sen and Dutt (1995) and Sanfey (1998), who consider the mark-up of the output price over marginal cost, though. An early approach to calculate the mark-up of the wage rate over the competitive wage in case of a unionised monopoly can be found in (Clark, 1984, eq. 1).
} 
the Pareto curve (in Figure 2). By contrast, when the union has total bargaining power $(\mu=1)$, the mark-up is maximal and the wage equals the total value added per worker, $w=\hat{w}:=(p f(L, K)-r K) / L$. Correspondingly, $\hat{w}$ is the highest acceptable wage for the firms, and the pair $(\hat{L}, \hat{w})$ represents the worst, individually rational contract for the employers' association, as it constitutes that Pareto efficient contract which leaves firms with zero profits; it thus represents the upper end of the Pareto curve (in Figure 2).

\section{$5 \quad$ Local Labour Market Negotiations}

In order to illuminate the effects that determine the bargaining outcome, characterised in Section 4, it is illustrative to contrast central labour market negotiations with the outcome under local negotiations. As explained above (see page 1), for a competitive output market, central negotiations may be identified with an endogenous output price under Walrasian market clearing; and local negotiations, with a fixed price. Thus, local negotiations may likewise be interpreted as central negotiations for a fixed output price. Accordingly, whenever convenient, we may refer to central (local) negotiations as negotiations under an endogenous (fixed) output price.

As a fixed output price, viz. local negotiations, represents the standard approach in the literature, this section recapitulates familiar results. This recapitulation helps to elucidate the consequences of an endogenous price formation for labour market bargains. In order to illustrate the difference, we now treat $p$ as some exogenously fixed output price. For a fixed price $p$ aggregate profits is maximized when $p f_{L}(L, K)-w=0$ holds. Hence, for a fixed output price, the $\phi$-term vanishes, and consequently the two first order conditions for maximization of the Nash product read $\operatorname{as}^{17}$

$$
\begin{aligned}
w: & \sigma(w) & =\frac{1-\mu}{\mu} \frac{w L}{\pi}, \\
L: & w & =\mu \frac{p f(L, K)-r K}{L}+(1-\mu) p f_{L},
\end{aligned}
$$

where $K$ equals the resulting level of capital demand: $K=\kappa(L)$. Equation (14) shows that the negotiated wage rate equals the weighted average of the (net) average and the marginal product of labour, implying that the wage rate exceeds the

\footnotetext{
${ }^{17}$ This result can be found in, for example, McDonald and Solow (1981), Creedy and McDonald (1991) or Bayındır-Upmann and Raith (2005).
} 
marginal product of labour, $w>p f_{L}$. Since (14) is equivalent to

$$
\frac{1-\mu}{\mu} \frac{w L}{\pi}=\frac{w}{w-p f_{L}}
$$

with $\pi=p f(K, L)-r K-w L$, it follows from equations (13) and (14) that

$$
\sigma(w)=\frac{w}{w-p f_{L}} .
$$

This equation characterizes the Pareto-curve in case of a fixed output price. If we denote the competitive wage rate by $w^{c}:=p f_{L}$, we may re-write equation (14) as ${ }^{18}$

$$
w=w^{c}+\mu \frac{p f(L, K)-r K-w^{c} L}{L} .
$$

The negotiated wage equals the competitive wage rate $(i . e$. the marginal product of labour) plus a mark-up which is given by the union's bargaining power times the potential industry profit (per worker) if the wage were equal to $w^{c}$.

\section{Effects of Centralisation}

Using the results from Sections 4 and 5, we are now prepared to compare the labour market equilibrium under central labour market negotiations, given by equations (10) and (11), with the equilibrium under local negotiations, determined by equations (13) and (14). From such a comparison we deduce the effects of, what we call for short, centralisation of labour market negotiations. As explained earlier, in this way, our comparison also helps to understand the discrepancy between labour market negotiations with endogenous price formation and those with an exogenous output price.

Recall that the equilibrium of the labour market may be defined as the solution of equations (10) and (11). Within a $(L, w)$-diagram each of both equations defines a downward sloping curve, and the intersection of both yields the bargaining outcome. Apparently, equations (10) and (13) coincide, implying that ceteris paribus the location of the $w$-Nash curve is unaffected by a change from local to central labour market negotiations. However, a comparison of equation (11) with equation (14) shows that the term $\phi$ drops out for local negotiations - thereby demonstrating that the endogeneity of the output price is captured by the term $\phi$. Consequently, while the location of the $w$-Nash curve is not affected by the degree of centralisation, the location of the $L$-Nash changes with $\phi$. For this reason we now

\footnotetext{
${ }^{18}$ See also Upmann and Müller (2013) for a similar formula.
} 
investigate the influence of the term $\phi$ on the equilibrium of the labour market. To this end we treat $\phi$ as if it were an exogenous parameter.

In order to see how the location of the $L$-Nash curve is affected by the degree of centralisation, we differentiate, for any arbitrary but fixed level $L$, this equation with respect to $\phi$. As the derivative of the left hand side of equation (11) with respect to $\phi$ equals $d w / d \phi=1-\mu>0$, a higher wage rate is ceteris paribus required to meet equation (11) — and because the $L$-Nash curve is downward sloping in a $(L, w)$-diagram, an increase in $w$ translates into a rightward shift of this curve. Since $\phi$ is negative, the appearance of $\phi$ shifts the $L$-Nash curve to the left; and since the $w$-Nash curve is downward sloping, a left shift of the $L$-Nash curve leads to a lower employment level along with a higher wage rate. As a consequence, under central negotiations the endogeneity of the output price provides an incentive for the bargaining parties to limit employment and to pay higher wages, when compared with local labour market negotiations.

This discrepancy between local and central negotiations is displayed in Figure 3. Therein the downward-sloping green curve represents the $L$-Nash curve for a fixed output price, denoted by $\mathcal{N}_{L}^{f}$; and the upward-sloping green curve, the corresponding Pareto curve, denoted by $\mathcal{P}^{f}$. (The upper index $f$ is associated with a fixed output price.) The resulting labour market equilibrium is thus achieved at $\left(L^{f}, w^{f}\right)$. This Figure 3 clearly displays the left-shift of the $L$-Nash curve induced by a change from local to central labour market negotiations; while the $w$-Nash curve (not displayed here) is ceteris paribus not affected by such a change. Note carefully that since the preferences of the employers' association are affected by the endogeneity of the output price, labour demand shifts from the ordinary labour demand curve $\mathcal{L}^{d}$ to the centralised labour demand curve $\mathcal{L}^{e}$. With preferences shifting to the left, the Pareto curve, by construction, does so as well. As a consequence, the endogeneity of the output price leads to a higher wage rate, $w^{N}>w^{f}$, but a lower employment level, $L^{N}<L^{f}$ under central labour market negotiations, when compared with local labour market negotiations (see Figure 3).

The left shift of the $L$-Nash curve can be explained as follows. While for a fixed output price, the preferences of the employers' federation coincide with the those of the representative (competitive) firm, this is no longer true for an endogenous output price. Realizing how the output price is affected in (a competitive) equilibrium, the employers' federation (during central labour market negotiations) acknowledges price effects induced by a labour market contract negotiated with the labour union. Formally, while for a fixed output price the slope of the indifference curves of the employers' federation are given by

$$
\frac{d w}{d L}=-\frac{w-p f_{L}(L, k(L))}{L}
$$




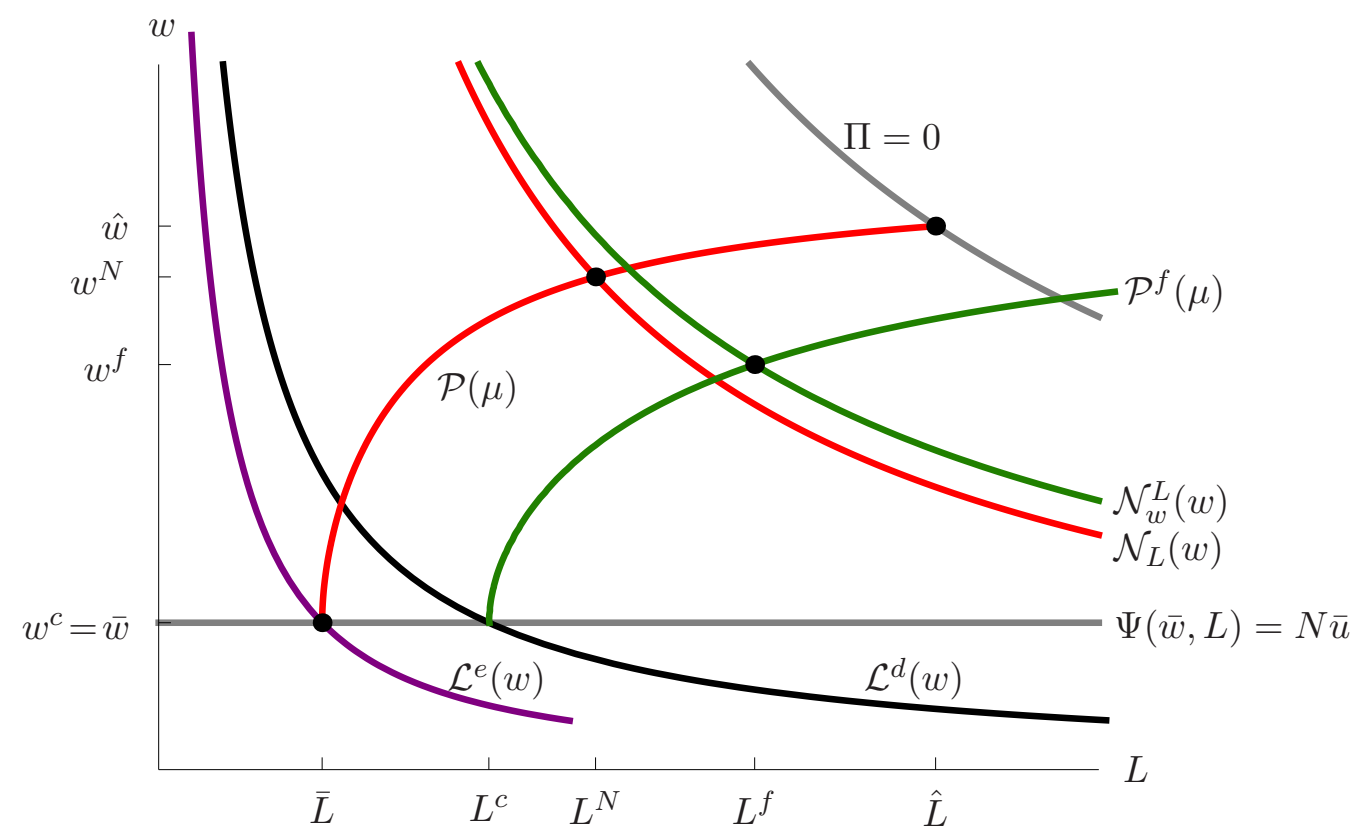

Figure 3: Bargaining outcome for an endogenous and an exogenous output price

and are thus upward (downward) sloping wherever $w$ falls short (exceeds) $p f_{L}$, the slope of its indifference curves equal

$$
\frac{d w}{d L}=-\frac{w-\left(p(z(L)) f_{L}(L, k(L))+\phi(L)\right)}{L}
$$

for a endogenous output price. Since $\phi<0$, it is as if the marginal product of labour were reduced by the endogeneity of the output price - and in this sense, the term $p f_{L}+\phi$ represents the marginal product of labour corrected for the equilibrium price effect on the output market: Depending on the elasticity of (output) demand, the output-price effect may be substantial, and may thus significantly affect the preferences of the employers' federation.

Since the centralised demand curve of the employers' federation lies to the left of the demand curve of the (representative) competitive firm, a change from firm-specific to aggregate preferences, viz. from local to central labour market negotiations, makes the $L$-Nash curve to shift leftwards; and in parallel, the Pareto curve must shift so as well. (Note that the preferences of the labour union are unaffected by a change in the degree of centralisation.) Also, since the $w$-Nash curve is not affected by the endogeneity of the output price, or formally by the $\phi$-term, the equilibrium with an endogenous output price must ceteris paribus be located on the original $w$-Nash curve - and therefore to the left of the equilibrium with fixed output price. As a consequence, when the parties on the labour market take into account the endogeneity of the output price, which applies to the case of central 
labour market negotiations, the anticipated price effect makes them negotiating for a lower employment level along with a higher wage rate.

Intuitively our result can be explained and summarized as follows. Consider a competitive industry with an endogenous output price. When the labour union and the employers' association understand the functioning of the output market, which they do (or should do) if they negotiate on a central level, they take into account the price effects induced by their agreement on the labour market. Thus, when labourmarket negotiations take place on a central level, the bargaining parties acknowledge that the final labour contract has an effect on aggregate supply, and thus on the equilibrium price on the output market. As a consequence, by taking into account the output-price effect resulting from a change in overall employment, the industry labour union and the employers' association accomplish to acknowledge (potential) price effects. Yet, these effects are disregarded by any single competitive firm, and are thus consequently ignored in labour market negotiations on a local scale. Since the industry labour union and the employers' association both have an interest in higher aggregate profits - as this increases the "cake" to be distributed - they both are interested in a higher output price, which can be achieved only by restricting output. This is induced by means of a suitable labour market contract, i. e., by negotiating for a lower employment level and for a higher wage (when compared with local bargains). In this way, they push (competitive) firms to produce a lower output, viz. into the direction of monopoly output.

Accordingly, the labour union and the employers' association accomplish to act on behalf of their clientele by taking into account the overall price effect. In this sense, in case of central negotiations the labour union and the employers' association internalise equilibrium price effects ("pecuniar externalities") — much in the same way as does a monopoly firm when acknowledging that marginal revenue falls short of the output price due to the endogeneity of the latter. This explains why centralised labour market negotiations lead to a lower employment level but to a higher wage rate (under Walrasian market clearing) when compared with negotiations for a fixed output price. Observe, though, that the bargaining parties are not able to make firms behave as if they were acting in a monopolistic cartel, because capital is still determined by competitive firms, equalizing the value of the marginal product of capital equal and its factor price.

We want to bring the following observation to the attention of the reader. Efficient labour market negotiations have sometimes been criticised that they bring about an employment level exceeding the competitive level (provided that the Pareto-curve has finite slope). Our approach, though, shows that this critique is disproportionate, because a strong employment effect materializes only if the out- 
put price is viewed as a given constant by the labour market parties. If, however, the parties on the labour market take into account the endogeneity of the output price, i. e. if negotiations take place on a central scale, they negotiate for lower employment levels; and this effect may be sufficiently strong so that the equilibrium employment level may ultimately fall short of the competitive employment level.

\section{Conclusion}

When an employer (firm) and its employees, respectively an employers' federation and an industry labour union, are free to bargain over the wage rate and the employment level, negotiations are expected to bring about an agreement on the Pareto curve. This qualitative result applies to both local negotiations, where each firm bargains with its employees, and central negotiations, where an employers' federation negotiates with an industry trade union. While it seems to be appropriate to ignore the difference between local and central labour market negotiations when further-reaching effects, such as output market competition or macroeconomic effects, are immaterial, this is inappropriate when labour market agreements lead to, for example, output market effects. Specifically, while there is apparently no difference between local and central negotiations for a fixed output price, this equivalence fails to hold when output market behaviour is acknowledged. With an endogenous output price, local and central labour market negotiations do no longer coincide.

In this paper we elaborated on this difference between local and central labour market negotiations. We argued that this difference can be translated into the discrepancy between the ignorance and the acknowledgement of output market effects. Our analysis demonstrates the difference between local and central labour market negotiations prevails, even under conditions of perfect competition (on the output market). Accordingly, we explored this difference for a competitive output market as this avoids mingling strategic behaviour of non-competitive firms with the effects of centralisation on the labour market. By assumption, in a competitive industry any single firm considers the output price as exogenously given data. Consequentially, in local negotiations a firm and its workforce behave competitively regarding the output price, i. e., they take the output price as exogenously given.

Yet, if the output price is actually determined endogenously, the assumption of a fixed output price is unjustified even if all firms behave competitively. While the endogeneity of the output price is reasonably ignored by a competitive firm and its employees in local negotiations, this endogeneity is arguably acknowledged by the bargaining parties on central scale: An employers' association acting on behalf of all firms and a labour union representing the interest of all workers arguably 
realise, and thus acknowledge, the effects of their behaviour, that is the effects of their contract, on subsequent competition on the output market. In other words, while for a fixed output price, the preferences of the representative firm and of the employers' federation coincide, this is no longer true for an endogenous output price, as only the federation takes into account the induced changes in the (equilibrium) output price. Due to this difference in economic understanding (or far-sightedness), the bargaining outcomes under local and central labour market negotiations do not coincide, even under conditions of perfect competition on the output market.

We show that central labour market negotiations result in a lower employment level (per firm) but a higher wage rate when compared with local labour market negotiations. This difference is formally reflected in a change of the familiar wage formula for efficient (Nash-) bargains: The acknowledged endogeneity of the output price results in a left-shift of the so-called Nash-curve (in an employmentwage-diagram). This left-shift of the Nash-curve reflects the parties' endeavour to acknowledge effects of changes in the equilibrium output price on aggregate firm profits. In this way the parties feature a behaviour similar to a monopolistic firm: While each firm behaves competitively, the federation seeks to push the industry into the direction of lower (aggregate) output. This is accomplished by negotiating with the trade union for a lower employment level - at the cost of a higher wage rate, though.

We believe that the observation that the 'standard' wage equation does not apply under central labour market negotiations, but must be suitably modified, is a vital theoretical result in its own. Beyond this, our findings have further, as we believe, important implications: First, efficient labour market models have sometimes been criticised on grounds of their common implication that the equilibrium employment level exceeds the competitive employment level (provided that the Pareto curve is increasing). Our finding, though, shows that this criticism may not be justified. If labour market negotiations take place at a central level, the resulting leftward shift of the wage-curve counteracts the increase in employment. If output demand is (locally) sufficiently elastic, employment under central labour market negotiations may fall short of the competitive employment level - even for efficient bargains. Second, the labour market equilibrium is determined by two straightforward equations, each of which is expressed in terms of the primitives of the model. Hence, with suitable specifications of the utility function, the production function and the inverse demand function, a testable structural form of the model can be obtained. Third, the modification of the labour market equations under central negotiations may have important consequences for empirical investigations. If one wrongly assumes that labour market negotiations take place on a local scale (or disregards the endogeneity of the output price), systematically distorted estimators for the underlying param- 
eters are obtained in return. Forth, in the same way, policy recommendations that are wrongly based on the assumption of local labour market negotiations (or of a fixed output price), may lead to systematically flawed recommendations for labour market policies.

Because our analysis shows that even competitive behaviour on the output market has substantial consequences for the equilibrium of the labour market, it seems fundamental to explore the consequences of imperfect competition on the output market for labour market negotiations. Since non-competitive firms, to some extent, take into account the output market effects, we conjecture that the difference between central and local bargaining becomes less significant the more firms acknowledge output price effects. Yet, this conjecture should be scrutinized thoroughly and may thus constitute a fruitful route for future research. 


\section{References}

Bayındır-Upmann, T. and M. G. Raith (2005). Unemployment and Pollution: Is One Policy Suited for Two Problems? The Economic Record 81 (255), 378-393.

Clark, K. B. (1984). Unionization and Firm Performance: The Impact on Profits, Growth, and Productivity. American Economic Review 74 (5), 893-919.

Creedy, J. and I. M. McDonald (1991). Models of Trade Union Behaviour: A Synthesis. The Economic Record 67(199), 346-359.

Cripps, M. W. (1997). Bargaining and the Timing of Investment. International Economic Review 38(3), 527-546.

Davidson, C. (1988). Multiunit Bargaining in Oligopolistic Industries. Journal of Labor Economics 6(3), 397-422.

Dobson, P. W. (1997). Union-Firm Interaction and the Right to Manage. Bulletin of Economic Research 49(3), 213-229.

Dowrick, S. (1989). Union-Oligopoly Bargaining. Economic Journal 99(398), 11231142.

Dowrick, S. (1993). Enterprise Bargaining, Union Structure and Wages. Economic Record 69(207), 393-404.

Fagnart, J.-F. and M. Germain (1997). Investment and Technological Choice in a Right-to-Manage Model. Journal of Economics (Zeitschrift fur Nationalokonomie) 66(3), 223-247.

Gerber, A. and T. Upmann (2006). Bargaining Solutions at Work: Qualitative Differences in Policy Implications. Mathematical Social Sciences 52(2), 162-175.

Hoel, M. (1990). Local versus Central Wage Bargaining with Endogenous Investments. Scandinavian Journal of Economics 92(3), 453-469.

Kraft, K. (2006). Wage versus Efficient Bargaining in Oligopoly. Managerial and Decision Economics 27(7), 595-604.

Lawson, N. P. (2011). Is Collective Bargaining Pareto Efficient? A Survey of the Literature. Journal of Labor Research 32(3), 282-304.

McDonald, I. M. and R. M. Solow (1981). Wage Bargaining and Employment. American Economic Review 71 (5), 896-908. 
Oswald, A. J. (1982). The Microeconomic Theory of the Trade Union. Economic Journal 92(367), 576-595.

Petrakis, E. and M. Vlassis (2000). Endogenous Scope of Bargaining in a UnionOligopoly Model: When Will Firms and Unions Bargain Over Employment? Labour Economics 7(3), 261-281.

Petrakis, E. and M. Vlassis (2004). Endogenous Wage Bargaining Institutions in Oligopolistic Sectors. Economic Theory 24(1), 55-73.

Sanfey, P. J. (1998). Bargaining, Efficiency Wages, and the Price-Cost Markup. Economics Letters 58, 193-197.

Sen, A. and A. K. Dutt (1995). Wage Bargaining, Imperfect Competition and the Markup: Optimizing Microfoundations. Economics Letters 48(1), 15-20.

Upmann, T. and J. Müller (2013). The Structure of Firm-Specific Labour Unions. Journal of Institutional and Theoretical Economics forthcoming.

Viner, J. (1931). Cost Curves and Supply Curves. Zeitschrift für Nationalökonomie 111, 23-46.

Vlassis, M. (2003). Wage Centralization and the Scope of Firm-Union Bargaining: 'Efficient Bargains' or 'Labour Demand'?. Manchester School 71 (3), 308-329. 


\section{Appendix A Comparative Statics of Competitive Factor Demand}

In order to evaluate the term $\phi$, we need to know the effects of a change in $L$ on the demand of capital and thus on output. To this end, we differentiate the equation system consisting of equations (1), (2), and (5) with respect to $L$, yielding

$$
\left[\begin{array}{ccc}
0 & p^{\prime} f_{K} & p f_{K K} \\
-1 & 0 & f_{K} \\
n & -1 & 0
\end{array}\right]\left[\begin{array}{c}
\frac{d q}{d L} \\
\frac{d z}{d L} \\
\frac{d K}{d L}
\end{array}\right]=\left[\begin{array}{c}
-p f_{K L} \\
-f_{L} \\
0
\end{array}\right]
$$

Solving for the derivatives we obtain:

$$
\begin{aligned}
\frac{d q}{d L} & =\frac{1}{|A|} p\left(f_{K} f_{K L}-f_{K K} f_{L}\right)>0 \\
\frac{d z}{d L} & =n \frac{d q}{d L}>0 \\
\frac{d K}{d L} & =\frac{1}{|A|}\left(p f_{K L}+n p^{\prime} f_{K} f_{L}\right),
\end{aligned}
$$

where $|A|:=-\left(p f_{K K}+n p^{\prime} f_{K}^{2}\right)>0$ denotes the determinant of the system matrix. (Note that $f_{K} f_{K L}-f_{K K} f_{L}>0$.) From these results we readily obtain

$$
\phi \equiv q p^{\prime} \frac{d z}{d L}=\frac{p z p^{\prime}}{|A|}\left(f_{K} f_{K L}-f_{K K} f_{L}\right)<0
$$

